\title{
Reducing the addictiveness of cigarettes
}

Jack E Henningfield, Neal L Benowitz, John Slade, Thomas P Houston, Ronald M Davis, and Scott D Deitchman, for the Council on Scientific Affairs, American Medical

Association

This report was presented by the American Medical Association (AMA) Council on Scientific Affairs to the AMA House of Delegates at its 147 th annual meeting in fune 1998. The recommendations at the end of the report were adopted by the House as $A M A$ policy.

See the accompanying editorial on pages 215 218 in this issue, as well as the Associated Press article on pages 315-319.

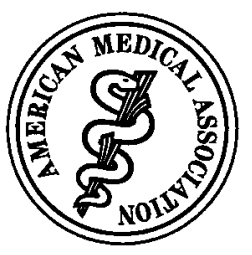

Correspondence and reprints: Dr LB Bresolin, American Medical Association, 515 North State Street, Chicago, Illinois 60610 , USA.

linda_bresolin@ama-assn.org
Abstract

Objective-To assess the feasibility of reducing tobacco-caused disease by gradually removing nicotine from cigarettes until they would not be effective causes of nicotine addiction.

Data sources-Issues posed by such an approach, and potential solutions, were identified from analysis of literature published by the US Food and Drug Administration (FDA) in its 1996 Tobacco Rule, comments of the tobacco industry and other institutions and individuals on the rule, review of the reference lists of relevant journal articles, other government publications, and presentations made at scientific conferences.

Data synthesis-The role of nicotine in causing and sustaining tobacco use was evaluated to project the impact of a nicotine reduction strategy on initiation and maintenance of, and relapse to, tobacco use. A range of potential concerns and barriers was addressed, including the technical feasibility of reducing cigarette nicotine content to non-addictive levels, the possibility that compensatory smoking would reduce potential health benefits, and whether such an approach would foster illicit ("black market") tobacco sales. Education, treatment, and research needs to enable a nicotine reduction strategy were also addressed. The Council on Scientific Affairs came to the following conclusions: (a) gradually eliminating nicotine from cigarettes is technically feasible; (b) a nicotine reduction strategy holds great promise in preventing adolescent tobacco addiction and assisting the millions of current cigarette smokers in their efforts to quit using tobacco products; (c) potential problems such as compensatory over-smoking of denicotinised cigarettes and black market sales could be minimised by providing alternate forms of nicotine delivery with less or little risk to health, as part of expanded access to treatment; and (d) such a strategy would need to be accompanied by relevant research and increased efforts to educate consumers and health professionals about tobacco and health.

Conclusions-The council recommends the following: (a) that cessation of tobacco use should be the goal for all tobacco users; (b) that the American Medical Association continue to support FDA authority over tobacco products, and FDA classification of nicotine as a drug and tobacco products as drug-delivery devices; (c) that research be encouraged on cigarette modifications that may result in less addicting cigarettes; (d) that the FDA require that the addictiveness of cigarettes be reduced within 5-10 years; (e) expanded surveillance to monitor trends in the use of tobacco products and other nicotine-containing products; (f) expanded access to smoking cessation treatment, and strengthening of the treatment infrastructure; and (g) more accurate labelling of tobacco products, including a more meaningful and understandable indication of nicotine content.

(Tobacco Control 1998;7:281-293)

Keywords: American Medical Association, addiction, nicotine, smoking cessation

\section{Introduction}

At the 1996 interim meeting of the American Medical Association (AMA) House of Delegates, a resolution introduced by the Minnesota delegation asked: "That the AMA develop and support legislation that would require tobacco companies to reduce the nicotine content in tobacco products sold in the United States by an appropriate, graduated, incremental annual reduction process so that tobacco products would be nicotine-free in six years"; and further, "that the AMA develop

Members and staff of the Council on Scientific Affairs at the time this report was prepared

Members: Ronald M Davis, Detroit, Michigan (chair); Joseph A Riggs, Haddon Field, New Jersey (chair-elect); Roy D Altman, Miami, Florida; Hunter C Champion, New Orleans, Louisiana; Scott D Deitchman, Decatur, Georgia; Myron Genel, New Haven, Connecticut; John P Howe, III, San Antonio, Texas; Mitchell S Karlan, Los Angeles, California; Mohamed Khaleem Khan, Boston, Massachusetts; Nancy H Nielsen, Buffalo, New York; Michael A Williams, Baltimore, Maryland; Donald C Young, Iowa City, Iowa. Staff: Thomas P Houston, Linda B Bresolin (secretary), Barry D Dickinson (assistant secretary), Chicago, Illinois. 
and support legislation that requires tobacco companies to accurately label their products indicating nicotine content in easily understandable and meaningful terms which have plausible, biological significance." A similar proposal had been issued by Benowitz and Henningfield. ${ }^{12}$ This report provides an analysis of the feasibility of such an approach to controlling cigarette-caused disease.

The driving force behind the nicotine reduction proposal is the current and projected scope of the public health problem caused by unmitigated cigarette smoking and continuation of the pipeline of new cigarette smokers. On the current course, as many as 25 million existing cigarette smokers in the United States will die prematurely because of tobacco use, many of whom will suffer from debilitating disease for many years before their deaths. ${ }^{3}$ Because disease risk is related to the amount of tobacco smoke exposure, this toll could be reduced if more smokers were able to reduce or stop smoking, thereby reducing their lifetime smoke exposure. ${ }^{45}$ Progress towards these goals could be enhanced by a combination of reducing the incentives to smoke, increasing the incentives to quit, and increasing the range and accessibility of options to help people achieve these goals.

It is critical to recognise that this approach is not the same as that embodied by the "Light" and "Ultra-light" cigarettes that currently exist in the market. While the public perceives these products as containing reduced levels of "tar" and nicotine, these cigarettes sustain high levels of nicotine addiction because they contain high levels of nicotine and enable people to sustain their nicotine addiction by "compensatory" smoking - for example, inhaling more deeply or smoking more cigarettes per day to achieve a stable level of nicotine in the body. ${ }^{1267}$ The current proposal under discussion would be intended to eliminate most smoking by providing cigarettes so low in nicotine that they could not sustain addiction.

Presently, progress in the United States toward reducing the prevalence of smoking and tobacco smoke exposure appears to be stalled, if not actually moving in the wrong direction. Adult prevalence of tobacco use has been approximately stable since $1990,{ }^{89}$ and the pipeline of new smokers from the ranks of young Americans (which exceeded a million new recruits per year for decades, but had appeared to stabilise in the 1980s) has been increasing since $1992 .{ }^{10-12}$ It would take nearly 10 years for projected new public health measures to produce a decline in smoking initiation in young people from about a million per year to a level of 500000 new smokers each year, even under the most optimistic projections and targets of the US Food and Drug Administration $(\mathrm{FDA})^{1112}$ and of supporters of the Proposed Resolution ("settlement") for a nationally legislated approach to tobacco litigation recently negotiated by several state attorneys general and major tobacco companies. ${ }^{13-15}$ Moreover, few analysts believe that this level of reduction would be achieved by either full implementation of the FDA's
Tobacco Regulation or by conditions of the Proposed Resolution. ${ }^{12} 1416$ Even if such a reduction were achieved, a pipeline of 500000 new cigarette smokers every year would still be unacceptable from a public health or humanitarian perspective.

This report examines the feasibility of reducing nicotine addiction by reducing the nicotine in cigarettes. The focus will be on cigarette smoking; however, the model and issues are generally applicable to other forms of tobacco use, including smokeless tobacco and cigars.

\section{Nicotine is an addicting drug}

Nicotine is a highly addictive drug that meets the same criteria for producing dependence as cocaine, heroin, and alcohol ${ }^{11} 1217$ It is more potent than most other addictive drugs, producing psychoactive and rewarding effects at acutely administered doses of less than $1 \mathrm{mg}$, and possibly as low as $0.2 \mathrm{mg}$ in nicotine-tolerant persons. ${ }^{18} 19$ Threshold doses for psychoactive and rewarding effects might be lower in non-tolerant children and adolescents. The addiction potential of a nicotine delivery system varies as a function of its total nicotine dosing capability, the speed with which it can deliver nicotine, the palatability and sensory characteristics of the system, the ease with which nicotine can be extracted, and the cost. Similar factors govern the risk of addiction to formulations of other addictive drugs. ${ }^{2021}$ The cigarette is an inexpensive, extremely effective nicotine delivery device, engineered to rapidly provide the user with nicotine, thus maximising the addicting and toxic effects of the drug. Cigarettes also deliver numerous other toxic chemicals, including many carcinogens. In contrast, transdermal nicotine patches deliver pure nicotine slowly and in relatively low doses, with none of the easily conditioned sensory stimuli that are presented by smoking cigarettes. Nicotine gum chewing requires considerably more active effort than cigarette smoking and is designed to provide acceptable but not highly pleasing flavours; the gum cannot deliver the high, rapid doses of nicotine provided by cigarettes. ${ }^{111222}$

The pathophysiology of nicotine dependence can be understood based on the effects of nicotine administration and withdrawal. ${ }^{21} 23$ The addicting actions of nicotine are mediated at least in part by the activation of nicotinic receptors in the brain and release of neurohormones. The brain mesolimbic dopaminergic reward system, which mediates the addicting actions of cocaine, is also involved in nicotine's addictive effects. The pathophysiological basis of nicotine addiction is now understood to include changes in the structure and function of the nervous system, including the development of increased numbers of brain nicotine receptors ("receptor up-regulation") and alterations in cerebral metabolism, brain neurohormone levels, and electroencephalogram patterns; these changes are produced by acute nicotine administration as well as by nicotine withdrawal. In addition, the effects of nicotine on the brain enable pulsed doses of 
nicotine to serve as a reinforcer, which can strengthen behaviours leading to its continued consumption by animals and humans despite adverse consequences. Finally, nicotine exposure can become a means to control mood, appetite, and body weight; sustain cognitive performance; and possibly serve other useful functions on which individuals may come to rely. ${ }^{11217}$

The American Psychiatric Association (APA) has identified two medical disorders that pertain to nicotine addiction. ${ }^{24}$ The first is nicotine dependence, which is a "pattern of repeated self-administration that usually results in tolerance, withdrawal, and compulsive drug-taking behavior." The essential feature of this disorder is a pattern of maladaptive use of the substance that continues despite adverse consequences. The second disorder is nicotine withdrawal, which causes "clinically significant distress or impairment in social, occupational, or other important areas of functioning." The essential feature of this disorder is a characteristic withdrawal syndrome due to the abrupt cessation of or reduction in the use of nicotine-containing substances. The syndrome includes craving for nicotine; irritability, frustration, or anger; anxiety; difficulty concentrating; restlessness; decreased heart rate; increased appetite or weight gain; sleep disturbance; and depressive symptoms. Nicotine withdrawal symptoms indicate that nicotine exposure has been sufficiently high and protracted to induce physiological dependence.

Most daily cigarette smokers exhibit both symptoms of nicotine dependence, and when abstaining, symptoms of withdrawal. ${ }^{11}{ }^{12} 25 \mathrm{An}$ individual can experience one or the other. ${ }^{24}$ For example, people who smoke fewer than six cigarettes per day ${ }^{26}$ are generally at a low level of physiological dependence and show few symptoms of withdrawal on smoking cessation. Most of these smokers can abstain from tobacco for several days, but the behaviour of many of them is highly reinforced by the pharmacological and conditioned effects of the cigarettes and they are unable to completely abstain, even in the face of harm and strong advice to quit. ${ }^{26}$ This situation is also seen in many people who are dependent on cocaine and at risk of losing their jobs, but who do not use at levels sufficient to establish physiological dependence. ${ }^{27}{ }^{28}$ Conversely, nicotine gum and patches can sustain physical dependence on nicotine but are of low potential for abuse. $^{22} 2930$ They are rarely used only to provide desirable psychological effects and are generally used at lower dosages and for shorter time periods than is recommended to aid smoking cessation. However, nicotine gum and patches can sustain tolerance and physiological dependence and are therefore useful in alleviating tobacco withdrawal symptoms and reducing cravings. ${ }^{23}$ 29-31

\section{Cigarette smoking: initiation, maintenance, and relapse}

Nicotine addiction underlies tobacco-caused mortality and morbidity, because it sustains tobacco use among most tobacco users and at high levels in the population. Cigarettes maximise the effects of nicotine by providing a convenient and effective means of nicotine storage, delivery, and dosage control, as well as by providing sensory stimuli that can acquire powerful conditioned reinforcing or responseeliciting effects in their own right as a function of repeated association with the effects of nicotine. ${ }^{32}{ }^{33}$ To better predict the possible benefits, as well as the limitations, of a nicotine weaning strategy, it is important to understand the role of nicotine in the initiation and maintenance of cigarette smoking, as well as its role in relapse to smoking after an individual has quit.

\section{INITIATION}

The factors that lead to initiation of tobacco use are diverse and include the seductive appeal of tobacco product marketing and advertising; the desire of some young people to emulate media stars; the use of cigarettes as a "badge" to indicate affiliation with a group or as a sign of personal rebelliousness; and the desire of some individuals to experience the pharmacological actions of nicotine, such as obtaining a "buzz", or controlling mood and body weight. ${ }^{34} 353637$ Although initial cigarette smoking is not without morbid risks, the primary short-term adverse health consequence is to establish nicotine addiction that leads to smoking for many years. A third to a half of all experimenters become addicted smokers. ${ }^{34} 3638$

Although young people have more limited financial resources than adults, young people generally initiate cigarette smoking with the more expensive, highly advertised brands of cigarettes, which have great badge value (Marlboro, Camel, or Newport), as opposed to the less expensive, "generic" brands. ${ }^{34} 3940$ Nonetheless, young people are sensitive to price, and increased prices can reduce their consumption. ${ }^{41}$ Philip Morris's unilateral 1993 drop in the wholesale price of its best-selling brand, an event known as "Marlboro Friday", made premium cigarettes more affordable to young people (because other producers followed suit) and likely contributed to the escalation of smoking in the young. ${ }^{34} 39$ Because the non-pharmacological factors noted above are most prominent in initiation, ${ }^{3436}$ taking the nicotine out of cigarettes alone is not likely to eliminate the initiation of social cigarette smoking. Nevertheless, if cigarette smoking becomes substantially less valued among regular users, it may lose much of its appeal to novices.

\section{MAINTENANCE}

A tobacco industry representative once said, "Nicotine is the sine qua non of smoking."11 Tobacco industry representatives have complained that taking the nicotine out of cigarettes would be tantamount to cigarette prohibition, thus defining cigarettes by virtue of their ability to deliver nicotine. ${ }^{42}{ }^{43}$ The extraordinarily high risk of morbidity and premature mortality attributable to cigarette 
smoking is due to the toxicity of the nicotine delivery system. The maintenance phase of nicotine dependence typically consists of approximately two decades of continuous, high-level exposure of the body to the toxic smoke constituents provided by approximately 20 cigarettes smoked daily. ${ }^{35}$ The disease risk is lower among people who smoke fewer cigarette per day and for fewer years, compared with life-long heavier smokers. ${ }^{4}$ The maintenance of cigarette smoking appears to be controlled very strongly by the pharmacological effects of nicotine.

During the maintenance phase, making a transition from tobacco to non-tobacco forms of nicotine delivery is difficult for many people. A tobacco company that considered extending its product line to include a nicotine patch concluded that the slow nicotine delivery characteristics of the patch technology would make it a weak competitor in relation to cigarettes. ${ }^{44}$ One opportunity to induce remission from smoking, then, is to make existing non-tobacco nicotine delivery systems more accessible and attractive to consumers and to develop even more acceptable, pure nicotine delivery systems. ${ }^{45-49}$

The most widely used "brands" among adult cigarette smokers have become the less expensive, "price-value" category of cigarettes ("generic"). Smoking less expensive cigarettes enables increasingly lower-income, addicted cigarette smokers to more economically maintain their nicotine addictions, albeit without the cachet of strongly branded, premiumpriced products. This diverges from the dominance of smoking brand-name cigarettes in the initiation phase..$^{39}$ Despite the health concerns of smokers and extensive marketing by tobacco companies to promote the so-called "ultra low" tar- and nicotine-yielding cigarettes (those with less than $0.2 \mathrm{mg}$ nicotine and less than $2 \mathrm{mg}$ "tar"), all brands of such cigarettes combined command less than $5 \%$ of the cigarette market in the United States. "Denicotinised" or "trace" nicotine cigarettes have been even less well received by consumers (eg, Next, Merit De-Nic, and Benson \& Hedges De-Nic). ${ }^{50}{ }^{51}$ It is well established by tobacco industry research, non-industry research, and consumer surveillance that the nicotine dosing characteristics of a cigarette type must fall within a relatively narrow range to sustain broad consumer use. ${ }^{11} 125253$ Thus, on this critical point, the tobacco industry appears to be in agreement with the public health community in concluding that the nicotine level in cigarettes is a critical determinant of consumption, and that, without nicotine, the consumption of cigarettes by society as a whole would be drastically reduced.

RELAPSE

Relapse is a critical issue because up to two-thirds of people who attempt to quit smoking relapse within a few days. ${ }^{54} \mathrm{~A}$ third of those who abstain for a year relapse in the following year. ${ }^{55}$ This high rate of relapse is partly due to the ubiquitous presence of tobacco products and advertising, which are stimuli that precipitate powerful cravings to resume the use of addictive drugs, ${ }^{17}{ }^{2856}$ as well as the relative inaccessibility of alternatives to tobacco. ${ }^{45-49}$ In addition, nicotine-deprived nicotinic receptors can produce powerful, physiologically based drives to reinstate smoking. In turn, loss of nicotine tolerance can result in heightened reinforcing effects from subsequently smoked cigarettes, as well as the ability to detect effects of lower doses, compared with when nicotine exposure was chronic, ${ }^{57}$ much as the detoxified heroin user re-experiences the reinforcing effects of heroin more powerfully than during the maintenance phase. $^{58} 59$

\section{A threshold for nicotine addiction}

The assumptions implicit in a nicotine reduction strategy are that: (a) there is a threshold nicotine exposure level that is necessary to sustain nicotine addiction; (b) it is technically feasible to manufacture cigarettes with low enough nicotine content to fall below this threshold for most people; and (c) smokers would not fully compensate for reduced nicotine levels by smoking more cigarettes or smoking each cigarette more intensely. A related issue is whether nicotine formulated in a less hazardous delivery system (such as nicotine medication) could be safely provided to moderate or eliminate compensatory oversmoking by addicted smokers who have only low-nicotine cigarettes available.

It is likely that a threshold level of nicotine sufficient to sustain addiction exists, although the exact level has not been determined, and the threshold level is likely to vary from person to person. The percentage of individuals finding it possible to develop or sustain nicotine addiction is likely to be related to the nicotine dose provided by the cigarettes. An operational target might be to set the threshold as one that would result in fewer than, for example, $10 \%$ of individuals obtaining adequate nicotine to sustain addiction. Whether the specific target chosen is a threshold value that will reduce the risk of establishing nicotine addiction to less than 1 in 10 or to less than 1 in 1000, a process of reconciliation of scientific data with public health concerns, and, in turn, with practical manufacturing considerations, will be necessary.

The original Benowitz-Henningfield proposal used nicotine intake by non-addicted "chippers" (those smoking occasionally, usually in social settings) to estimate a nicotine level that sustains addiction. ${ }^{1}$ It is recognised, however, that chippers are self-selected to be chippers, and their dose-related response to nicotine may differ from that of heavier smokers. Specifically, it cannot be assumed that the low levels of nicotine to which chippers are exposed, corresponding to approximately $5 \mathrm{mg}$ per day, will not be addictive for a previously addicted smoker whose nicotine exposure has been reduced. However, some data suggest that a systemic dose of $0.2 \mathrm{mg}$ nicotine per cigarette would be a threshold level for reinforcement. Human discrimination studies using nicotine nasal spray indicate a threshold 
level of about $0.15 \mathrm{mg}(2 \mu \mathrm{g} / \mathrm{kg})$ in nonsmokers and $0.30 \mathrm{mg}(4 \mu \mathrm{g} / \mathrm{kg})$ in smokers. ${ }^{60}$ Significantly different discrimination behaviour in smokers between $2 \mu \mathrm{g} / \mathrm{kg}$ and placebo during generalisation testing suggests that the "just noticeable difference" of nicotine discrimination is no more than $2 \mu \mathrm{g} / \mathrm{kg}$, or about 0.15 mg. ${ }^{61}$

Other evidence raises the possibility that even lower doses of nicotine delivered by cigarette smoking (as opposed to pure nicotine infusions) could be reinforcing. For example, studies of oral alcohol use and intravenous drug self-administration by monkeys support this concept. After the drugs are established as reinforcers, previously non-reinforcing drug concentrations will sustain behaviour; the ability of very low concentrations to sustain behaviour appears to be facilitated by the association of environmental stimuli with the drugs. ${ }^{62-64}$ Moreover, a study of intravenous selfadministration of nicotine paired with environmental stimuli in rats, found that selfadministration occurred at doses as low as $3.75 \mu \mathrm{g} / \mathrm{kg}$. ${ }^{65}$ More research is needed to assess the threshold for reinforcing effects of nicotine and the effects of nicotine reduction on addictive smoking behaviours. Analysis of the issue suggests that there will be some threshold value that would provide a basis for guiding the extent of nicotine reduction.

\section{Concerns about a nicotine reduction strategy}

A variety of potential concerns exist about the implementation and consequences of a nicotine reduction strategy. The following is not intended to be exhaustive but rather to provide some perspective on prominent concerns and issues.

CAN A THRESHOLD DOSE FOR NICOTINE ADDICTION BE IDENTIFIED?

The tobacco industry has challenged the concept that there is a threshold dose for nicotine to cause addiction. To support this view, it has cited the inability of the FDA or its advisory committee to identify a specific addicting dose threshold. The tobacco industry also has argued that a "threshold dose of nicotine [for addictive effects] cannot be determined." 12 The tobacco industry supported this proposition in its comments to the FDA by selectively citing comments of the FDA Drug Abuse Advisory Committee, which addressed the issue in $1994 .{ }^{11}{ }^{12}$ In these comments, the representatives of the tobacco industry did not address the central problem actually raised by the committee, which was its concern that any level of nicotine might contribute to sustained tobacco use in some individuals, and that children in particular might be more sensitive to lower doses of nicotine than would be predicted by studies of adult cigarette smokers. The lack of precision in ability to determine an absolute threshold below which addiction is unlikely to occur and above which addiction readily occurs should not pose any more of an obstacle than the analogous problem of determining the maximum allowed alcohol content for non-alcoholic beer or the maximum levels of contaminants permitted in food products. The value proposed by Benowitz and Henningfield (in which a maximum of $0.17 \mathrm{mg}$ nicotine could be absorbed into the body of the smoker per cigarette) probably represents the highest level that should be considered. The actual level that would be set for a threshold in labelling a tobacco product as "denicotinised" probably should be lower than the Benowitz-Henningfield value to minimise the possibility that young and non-tolerant people would experience a nicotine effect that might lead to sustained use of tobacco.

\section{IS A REDUCED NICOTINE CIGARETTE}

TECHNICALLY FEASIBLE?

The tobacco industry has demonstrated that it is possible to produce tobacco with a wide range of nicotine concentrations, from the trace levels found in Philip Morris's "denicotinised" cigarette brand called "Next", to the levels of other brands that are higher in nicotine content. ${ }^{66}$ The sensory characteristics of denicotinised cigarettes were sufficiently comparable to those of conventional cigarettes that both tobacco industry ${ }^{67}$ and nonindustry researchers ${ }^{32}$ found that they served as acceptable placebo cigarettes in studies intended to assess the contribution of nicotine to the initial effects of cigarette smoking. The National Cancer Institute's effort to develop "safer" cigarettes in the 1970 s also produced a line of cigarettes that varied widely in nicotine concentrations. ${ }^{69}$ More recently, as part of a contract with the National Institute on Drug Abuse, small consumer-products companies are developing cigarettes that are similar in many sensory characteristics to conventional cigarettes but have extremely low levels of nicotine. The plethora of techniques already patented and tested for adjusting nicotine levels of cigarettes have been described in detail in tobacco industry documents and elsewhere. ${ }^{11} 1270-76$

\section{WOULD COMPENSATORY SMOKING REDUCE THE} POTENTIAL HEALTH BENEFITS?

Compensatory over-smoking is often raised as a potential adverse consequence of a nicotine reduction strategy, particularly for alreadyaddicted smokers. The idea is that to maintain a desired intake of nicotine, the addicted smoker would smoke each cigarette more intensely or smoke more cigarettes, thereby sustaining levels of toxin exposure comparable to (or higher than) those observed in individuals smoking higher nicotine providing cigarettes. ${ }^{77-79}$ This is believed to occur with the so-called "lower tar" and "lower nicotine" cigarettes currently on the market. ${ }^{77}{ }^{79-82}$ The phenomenon of compensatory smoking has been amply demonstrated in short-duration studies in which smokers were switched from higher yield to lower yield commercial cigarettes or when the number of cigarettes to which they had access had been restricted. ${ }^{83} 84$

It should be noted, however, that commercial cigarettes contain substantial 
nicotine in the tobacco. There is just as much nicotine in the tobacco of "low-yield" cigarettes as in high-yield cigarettes, and it is fairly easy for the smoker to alter puff rate or smoking intensity, or block ventilation holes, to substantially increase nicotine yield from normally low-yield cigarettes. ${ }^{65}$ This would not be the case after implementation of a nicotine reduction strategy, because only low or negligible amounts of nicotine would be available for extraction from the tobacco in cigarettes. One study compared smoking research cigarettes of low- or high-nicotine content, in which the number of cigarettes smoked per day was fixed. ${ }^{86}$ The data revealed some evidence of over-smoking based on increased carbon monoxide levels, but the extent of over-smoking was modest (about $25 \%$ ) with an overall fourfold reduction in nicotine exposure. This suggests that there is a limit to how intensely a smoker will over-smoke cigarettes.

Most experimental studies on switching from high-yield to low-yield cigarettes were short-term, lasting days to a week. The only study that examined switching over 12 weeks ${ }^{87}$ reported a $30 \%$ reduction in levels of nicotine and cotinine (a nicotine metabolite) with no increase in cigarette consumption or carbon monoxide levels, suggesting that, whereas partial compensation occurred, there was no harmful oversmoking of the low-yield cigarettes. Another study, which used "nicotine fading" (switching to brands with progressively lower yields of nicotine as part of a smoking cessation program), found a decrease in cotinine by $38 \%$ and carbon monoxide by $25 \%$ over the three-week study. ${ }^{88}$ Thus, even though compensatory over-smoking is a concern, the extent may not prove to be great, and the accompanying risk of increased temporary exposure to tobacco smoke toxins may be acceptable if the ultimate benefit will be cessation within a few years. Additionally, there is little evidence from either laboratory research or attempts to market denicotinised cigarettes that such cigarettes would sustain use in a substantial percentage of smokers. Nonetheless, ongoing research would be needed to evaluate the exposure of cigarette smokers to carbon monoxide and other toxins during the implementation of a nicotine reduction program, to minimise the possibility of adverse effects.

One way to avoid compensatory oversmoking would be to make nicotine more available via less hazardous delivery systems. ${ }^{45} 4648$ At this time, pure nicotine is available over the counter as nicotine gum and patches. Conceivably, nicotine in other medicinal forms, as well as nicotine delivered via genuinely "smokeless delivery devices", might become available. The addicted smoker could be encouraged to use nicotine from these sources at the same time that nicotine in cigarettes is being reduced. ${ }^{13}$
ARE THERE ADVERSE OR UNMANAGEABLE NICOTINE-RELATED HEALTH CONSEQUENCES FROM GRADUAL NICOTINE REDUCTION FROM TOBACCO?

No evidence exists that gradual reduction of nicotine from cigarettes would produce health problems not manageable through behavioural intervention strategies, nicotine-delivering medications, and/or other medications. Acute nicotine deprivation in physically dependent tobacco users can precipitate withdrawal symptoms that can be severely behaviourally, emotionally, cognitively, and physiologically disrupting. ${ }^{89} 90$ Sudden nicotine abstinence also can precipitate symptoms of depression in people with histories of major depressive disorder. $^{9192}$ The possibility exists that acute nicotine abstinence might exacerbate symptoms of other forms of psychiatric illness or complicate the management of other forms of drug dependence treatment, but this has not been well studied..$^{93-97}$ It is important to recognise that nicotine withdrawal symptoms are treatable $\mathrm{e}^{90-98}$ and need not pose inherent barriers to a nicotine reduction strategy.

The main issue, from a medical perspective, does not seem to be that gradual nicotine withdrawal will precipitate adverse health conditions that cannot be managed, but rather that appropriate medical interventions would not be readily available to those in need. This problem is compounded by the fact that smokers have disproportionately lower income and have less access to health care resources than the general population. Thus, strengthening the treatment infrastructure is an important component of a nicotine reduction strategy (see below).

WOULD THE SAFETY AND TOXICITY PROFILE OF NICOTINE SUPPORT A POLICY THAT ENCOURAGED THE TRANSITION FROM TOBACCO TO ALTERNATE NICOTINE DELIVERY SYSTEMS?

Some may contend that nicotine itself is hazardous and that its use should not be encouraged because some addicted smokers may transfer their dependence to medicinal nicotine. Although this is possible, addiction to nicotine without exposure to tobacco combustion products is greatly preferable to smoking. ${ }^{3198-100}$ Nicotine is not without detrimental effects, particularly during pregnancy, and possibly in the presence of cardiovascular disease. ${ }^{101-103}$ However, by far the most common severe health effects in smokers are caused by other tobacco smoke toxins. Nicotine delivered by cigarette smoke is likely to be more toxic than nicotine delivered from slower-release medications because high peak levels and the fast rate of rise of nicotine levels associated with smoking produce more intense physiological effects for the same available dose compared with nicotine patches or gum.

WOULD NICOTINE REDUCTION FOSTER ILLICIT TOBACCO SALES?

The flowering of an illicit market ("black market") in higher nicotine cigarettes has been raised as a potential adverse consequence of a nicotine reduction proposal. ${ }^{48104} 105$ For 
example, the Proposed Resolution negotiated between some of the states' attorneys general and the major cigarette producers in 1997 would allow the FDA to require reductions of nicotine in tobacco products only if the agency could provide evidence that this would not lead to a significant black market in unregulated tobacco products. Currently, it appears that tobacco product manufacturers tolerate illicit cigarette markets and benefit from them. ${ }^{105} 106$ It is not clear that a substantial illicit market would be possible without some level of complicity by tobacco producers or marketers. 48107

It is also important to recognise that illicit markets are not all-or-nothing phenomena. For example, some level of smuggling of cigarettes from states with low tobacco taxes to states with high tobacco taxes has existed for many years. ${ }^{105} 108$ The practical judgment that policy makers would have to make is the extent to which a possible increase in a contraband tobacco market would be less important than the probable substantial reduction in death and disease caused by tobacco products when considered in total, factoring in the ways in which contraband could be suppressed by intensifying anti-smuggling law enforcement activities and by enlisting improved cooperation of manufacturers.

\section{Components of a nicotine reduction strategy}

The primary barriers to removal of nicotine from cigarettes appear to be social and political, although problems such as inadequate educational, research, and treatment infrastructures also could hinder successful implementation. To effect a nicotine reduction strategy in such a way as to achieve the greatest lowering of tobacco-caused disease and to minimise undesirable consequences, a variety of components must be considered.

EDUCATION: GENERAL AND MEDICAL

Successful implementation of a strategy to eliminate nicotine from cigarettes requires educating both health professionals and the general public. ${ }^{109110}$ Inadequate education about tobacco results in the propagation of lore and anecdotes regarding health effects and treatment needs. It also allows unfounded concerns as to whether tobacco abstinence will undermine the treatment of psychiatric diseases and alcohol and illicit drug addictions..$^{94} 95111$ Health professionals will need more education about how to diagnose and manage health problems that could be precipitated by nicotine withdrawal from cigarettes. ${ }^{109110112}$ Moreover, it is possible that, in the future, a variety of medical disorders will be treated with medications containing nicotine or nicotine analogues. ${ }^{113} 114$ There is no reason to believe that the medical benefits of nicotine use could not be derived through the use of pure nicotine-containing medications without exposure to tobacco products. Similarly, a reluctance to recommend safe forms of nicotine (because of high cost, non-availability, or irrational fears) to former smokers may be to the detriment of some former smokers' health. Thus, it is important to educate both consumers and health professionals about the goals and realistic expectations of, and alternate strategies to, a nicotine reduction policy before and during implementation.

LABELLING IMPLICATIONS

As nicotine levels are reduced in cigarettes, it would be useful for a wide range of tar and nicotine deliveries to be available in different brands up to the permitted ceiling, to facilitate the efforts of individuals who will want to wean themselves more rapidly from tobacco. ${ }^{6}{ }^{46} 115$ As has been observed elsewhere, the seemingly wide range of choice that consumers have today is actually little more than a cigarette marketing strategy based on machine yields of cigarettes that provides relatively little variation in nicotine levels actually obtained by human cigarette smokers. ${ }^{6}{ }^{50}$ However, it is possible to provide consumers with meaningfully labelled cigarettes. Apparent consumer demand (approximately two-thirds of American cigarette smokers currently smoke cigarettes that are rated by machines as yielding low tar and nicotine) should provide a strong product development incentive to actually provide such cigarettes. ${ }^{60}$

Cigarettes with nicotine levels lower than those deemed generally adequate to cause and sustain addiction could be labelled analogously to decaffeinated coffee or non-alcoholic beer. In both cases, special processes have been used to remove most of the psychoactive substance normally present.

The AMA has advocated that all cigarettes be labelled as addicting (AMA Policy $\mathrm{H}-495.997$, AMA Policy Compendium), as cigarettes marketed by the Liggett Group in the United States have been since 1997. Cigarettes in Canada and Australia are also labelled with rotating warnings that include the word "addiction." 116117 Even a cigarette that does not deliver readily addicting levels of nicotine could serve as the first step in the process of developing addiction to other nicotine products; therefore, such cigarettes should not be exempt from an addiction warning, although it is possible that the warning might be modified for such cigarettes-for example, "Use of these cigarettes may lead to nicotine addiction."

TREATMENT INFRASTRUCTURE

Many smokers achieve and sustain tobacco and nicotine abstinence: about 1.3 million or $2 \%$ to $3 \%$ of American cigarette smokers each year achieve the criterion of a year of continuous abstinence. ${ }^{55}$ Although studies have shown that about $90 \%$ of former smokers achieved abstinence without treatment support (including nicotine medications), ${ }^{118}$ the facts remain that: (a) more than $90 \%$ of people who try to quit smoking relapse within a year, with most relapsing within about a week ${ }^{54} 55$; (b) behavioural and pharmacological treatment improves the odds of success ${ }^{90} 98119$; (c) some presently unknown percentage of people who 
quit smoking appear to require extended nicotine maintenance to feel "normal" and to be fully functional at their jobs and in their ability to interact socially; and (d) it is plausible that some people who have grown up under the behavioural and physiological influence of nicotine will never be fully or comfortably functional without continued nicotine administration. These observations support the conclusion that many cigarette smokers could benefit from some form of intervention to achieve abstinence from tobacco products. Unfortunately, the treatment infrastructure of our nation is woefully underdeveloped with regard to smoking cessation. ${ }^{14}{ }^{120-124}$ Cigarettes are readily available to most people 24 hours per day, but access to effective smoking cessation aids is much more limited. A person might have to wait months for the start of a smoking cessation clinic group, if the service is even offered in his or her locale.

The foregoing observations suggest that the relative lack of treatment infrastructure and alternate nicotine delivery systems is a barrier to reducing nicotine from cigarettes. Treatment infrastructure needs have been discussed in detail elsewhere. ${ }^{115}{ }^{120-127}$ Briefly, these needs include a mechanism to determine which treatments are effective, modes of treatment delivery, the ability to deliver treatment to those with increased need along a stepped-care model, mechanisms of payment for treatment, and a means of determining which treatment modalities are worthy of government endorsement and health insurance coverage. This infrastructure would ideally be in place when the nicotine weaning policy is implemented and would probably be required for decades following implementation. It may be necessary to pace the speed of nicotine reduction to the development of adequate treatment infrastructure. In particular, people with higher levels of nicotine dependence are likely to have stronger needs for formal treatment to help them cope with the reduction of nicotine in cigarettes..$^{90-98}$

ALTERNATE NICOTINE-DELIVERING MEDICINES

Alternate forms of nicotine delivery should be at least as accessible as cigarettes. ${ }^{46}{ }^{48}{ }^{49} \mathrm{~A}$ major reduction of barriers to alternate forms of nicotine delivery was the marketing of nicotine patches and gum as over-the-counter (OTC) products, which has contributed to increased smoking cessation. ${ }^{128} 129130$ Nonetheless, restrictions on the packaging, pricing, and points of sale (gas stations and convenience stores, for example, are prohibited from selling nicotine medications), as well as other factors, mean that it is still much easier to buy a pack of 20 cigarettes (in most states costing about \$2) than to purchase the minimal package size of nicotine medications (about $\$ 30$ for 48 pieces of gum). ${ }^{46-49}$ Whereas tobacco companies have been relatively free to manipulate taste and other sensory characteristics to maximise the appeal of their products, improving the acceptability of nicotine medications would require years of regulatory review and further testing after the product modifications had been developed and proposed to the FDA. ${ }^{40} 45-49131$
Moreover, anything but relatively minor alterations to existing OTC nicotine-delivering products could cause them to revert to a prescription-only status. ${ }^{48} 100$

Regulatory approaches to medicinal forms of nicotine would clearly need to be revised in coordination with any approaches taken with tobacco products to enable the removal of nicotine from cigarettes in a timely manner. ${ }^{46}$ Similarly, although it is beyond the scope of this report to discuss the issue regarding other tobacco products, a nicotine reduction strategy for cigarettes implies that all forms of tobacco would be considered for such a policy and that efforts would be made to ensure that reduced access to high-nicotine-yielding cigarettes did not inadvertently stimulate increased use of other tobacco products. The importance of more consistent regulation across tobacco products to avoid such "product substitution" was discussed at the American Cancer Society's conference on cigars in June 1998, in which it was concluded that because the FDA has asserted jurisdiction over cigarettes and smokeless tobacco but not over cigars, ${ }^{11}{ }^{12}$ cigars might become relatively more accessible and appealing than cigarettes and smokeless tobacco. ${ }^{132}$

A more controversial issue is the degree to which alternate nicotine-delivery systems need to be competitive with cigarettes with respect to their nicotine dosing characteristics. ${ }^{48}{ }^{49} \mathrm{~A}$ wide range of nicotine dosing systems are likely to be required to meet the needs of the diversity of cigarette smokers who cannot stop smoking. ${ }^{133}$ However, this does not mean that all nicotine-delivering systems must be treated equally from a regulatory perspective. ${ }^{46-49}$ Although there is no question that non-tobacco forms of nicotine exposure are less toxic than tobacco forms, it is also a mistake to equate all non-tobacco nicotine delivery forms as equally toxic and equally addictive (or non-addictive) and, therefore, requiring similar regulation. ${ }^{22} 49134$ Analgesics range from inexpensive single-dose packages that can be procured in almost any retail setting (such as aspirin), to those restricted to pharmacies (certain combination analgesic medications), to those regulated under the provisions of the Controlled Substances Act, such as morphine. A similar range of nicotinedelivering medications may be needed, ranging from readily available, very safe forms with a very low additive potential to much more aggressive nicotine-delivering forms that might be treated as prescription substances. Such developments are technically feasible, but regulatory issues presently serve as disincentives and obstacles to the rapid development and marketing of such products. ${ }^{49} 135$

RESEARCH INFRASTRUCTURE

Complementary and supportive research is needed to enable the most effective implementation of a nicotine reduction approach and to implement such an approach without unintended consequences. ${ }^{14} 40131$ 136-140 Thus, there is a need for expanded research capacity and commitment at the federal level in the fol- 
lowing areas. (a) Surveillance research that would be rapid and provide comprehensive monitoring of the use of all forms of nicotine is needed to allow midcourse policy corrections, to guide regulation, and to enable more rapid dissemination of new treatment approaches. In this regard it is worth noting that at least one major tobacco company conducts monthly consumer use and attitude tracking surveys. ${ }^{139}$ (b) Basic research on the pathophysiology and development of nicotine dependence is important, because it promises to provide a rational basis for improved prevention and treatment efforts. (c) Prevention and treatment research is needed to complement work done by the private sector to develop and evaluate new prevention and treatment approaches. (d) Regulatory research by the FDA would be critical to ensure that it could keep regulations consistent with the science underlying existing and new tobacco products and nicotine delivery systems - for example, research on issues such as the means by which product modification affects nicotine dosing characteristics.

\section{A comprehensive approach to remove nicotine from cigarettes}

During the past two decades, two seemingly diametrically opposed approaches to tobacco modifications have been proposed for reducing the death and disease caused by tobacco use. The first is to decrease the exposure to toxins by increasing the ratio of nicotine to tar and other toxins delivered by cigarette smoking. ${ }^{140}$ The main problem with this approach is that it would not promote cessation and could plausibly be expected to undermine efforts to prevent the development of addiction to cigarettes. ${ }^{1}$ The second approach is to eliminate nicotine from cigarettes, while providing easy access to treatment (including nicotine medication). These approaches may be reconcilable: an analysis by Warner, Slade, and Sweanor ${ }^{45}$; a report from a Roundtable of the United Nations Conference on Trade and Development (UNCTAD) of the United Nations ${ }^{141}$; and a seminar sponsored by the Health Education Authority in the United Kingdom $^{142}$ discussed the feasibility of reducing the toxicity and availability of tobacco products while simultaneously increasing the range and accessibility of nicotine-delivering medications.

REGULATION OF ALL NICOTINE-DELIVERING PRODUCTS MUST BE CONSISTENT

There has been much discussion of the need for a "level playing field" for nicotine products, be they medications from pharmaceutical companies or cigarettes and snuff from tobacco companies. ${ }^{44-49} 135$ 141-143 The application of more consistent standards of regulation and oversight across all nicotine products, such that less toxic and addictive nicotine-delivering products (for example, nicotine gum and patches) would be more easily accessible than more addictive and toxic products such as cigarettes, smokeless tobacco, and cigars, is needed. ${ }^{142}$ This concept is not meant to advocate identical standards for tobacco and treatment products; such an approach could trigger the banning of cigarettes, ${ }^{46-49} 135$ which we do not propose. An important goal should be to reverse the present regulatory paradox, whereby the most addictive and toxic forms of nicotine delivery are marketed more liberally than life-saving nicotine replacement medications. ${ }^{45} 134$ Besides "levelling the playing field", another potential benefit of "coregulation" of tobacco products and tobacco dependence treatment products would be that their regulation would be effected by a single regulatory agency (eg, the FDA), thereby enabling coordination of regulatory approaches for tobacco and treatment products.

Every possible step should be taken to decrease demand for the most toxic products, to provide incentives for developing nicotine dependence medications, and to continue in the direction of reducing illness and death from tobacco. The toxicity of cigarettes should be reduced to the extent allowed by current technology, without permitting claims for any safety benefits, because all forms of smoking incur marked risks. ${ }^{6}{ }^{141142}$ Setting future targets for maximum delivery of toxins such as carbon monoxide and tobacco-specific nitrosamines would create incentives for tobacco manufacturers and entrepreneurs to conduct research to achieve these goals. Djordjevic, Brunnemann, and Hoffman ${ }^{144}$ have documented that available production processes can greatly reduce the levels of tobacco-specific nitrosamines in moist snuff. Standards should be set on the maximum delivery of such cancercausing toxins. ${ }^{141}$

Finally, improvements in the nature and use of nicotine medications should be stimulated, not stifled..$^{46-49} 135$ To stimulate the development and appropriate marketing of new products for consumers, all products and strategies employed for tobacco cessation or reduction of tobacco use must be reviewed regularly (every one to two years). The 1996 review of smoking cessation approaches by the US Agency for Health Care Policy and Research ${ }^{98}$ provides a good model for such an approach. Presently, only drug products for smoking cessation are evaluated for efficacy by the FDA. There exists no regular mechanism for review of behavioural treatments, dietary supplements, or new medical devices. Moreover, consistent standards must be set for marketing and claims, so that consumers are provided accurate information about and adequate access to the broadest range of effective products as soon as possible, but are not inundated with worthless or harmful products that waste resources and may discourage their efforts to quit.

\section{Conclusions}

A nicotine reduction strategy holds tremendous promise as a way to prevent adolescent nicotine addiction and to assist the millions of addicted smokers to quit using tobacco products. However, such a strategy can work only if all cigarettes are nicotine-tapered at the same time. Research is needed in advance of such a policy to better determine the threshold 
levels of addicting dosages of nicotine and to examine the extent of compensatory oversmoking that occurs when nicotine content is tapered. Other research, similar in principle to current postmarketing surveillance approaches for new drug products, would then be needed during the tapering process to document changes in cigarette consumption, exposure to nicotine and various tobacco toxins, and rates of tobacco-use initiation and addiction among adolescents. Such monitoring would allow analysis of the nicotine reduction strategy, as the policy is implemented, and would allow feedback to make adjustments in policy as needed.

The regulation of nicotine should not be the only focus of tobacco product regulation by the FDA. Nicotine regulation per se is only one of the many potentially useful approaches that the FDA could employ to reduce the death and disease caused by tobacco products, as tobacco's toxic "chemical soup" and dozens of known carcinogens in tobacco (whether smoked or chewed) are responsible for the lethal outcome of tobacco use. For example, the FDA could make sure consumers are better informed about tobacco products, could set standards for maximum toxin levels delivered to consumers by tobacco products, and could facilitate the introduction of new nicotine delivery devices that pose lower disease risks. These fundamental approaches are not incompatible with ultimately reducing the nicotine content of tobacco.

Removing nicotine from cigarettes and other tobacco products could drastically reduce the nation's burden of tobacco-caused disease, reducing lung cancer, chronic obstructive pulmonary disease, and a number of other common ills to relatively low levels because tobacco products would be "non-addicting" and chronic use would presumably fall dramatically. Such an action would not only be important in preventing future nicotine addiction but could also substantially reduce the morbidity and premature mortality that is expected to develop among current tobacco users. It is already technically feasible to produce nicotine-reduced tobacco products. Alternate forms of nicotine delivery to which people might transition are either already available or could be developed. With or without such an approach, this nation needs to develop an infrastructure that makes it as easy for people to obtain treatment for tobacco dependence as to obtain disease-causing tobacco products. ${ }^{45-49} 135$ Similarly, with or without such a nicotine reduction approach, it would be important to provide better education to consumers and health professionals regarding the health effects of tobacco use, the benefits of cessation, and the means to achieve and maintain abstinence.

\section{Recommendations}

The following statements, recommended by the Council on Scientific Affairs, were adopted as AMA policy at the June 1998 AMA Annual Meeting.
1. The AMA reaffirms its position that all tobacco products are harmful to health, that there is no such thing as a safe cigarette, and that complete cessation of tobacco use should be the goal for all tobacco users.

2. The AMA reaffirms its position that the FDA does have, and should continue to have, authority to regulate tobacco products, including their manufacture, sale, distribution, and marketing.

3. The AMA reaffirms its position that nicotine is a drug and tobacco products are drug-delivery devices.

4. The AMA encourages the FDA and other appropriate agencies to conduct or fund research on how tobacco products might be modified to facilitate cessation of use, including elimination of nicotine and elimination of additives such as ammonia that enhance addictiveness.

5. The AMA encourages the FDA to assert its authority over the manufacture of tobacco products to reduce their addictive potential at the earliest practical time, with a goal for implementation within five to 10 years.

6. The AMA supports and will advocate for appropriate surveillance approaches to measure changes in tobacco consumption, changes in tobacco-related morbidity and mortality, uptake of tobacco use by young people, and use of alternative nicotine delivery systems.

7. The AMA continues to support development of an infrastructure for tobacco dependence treatment, education of health care professionals and the public about the effects of tobacco use and the benefits of cessation, and ready availability of and insurance coverage for pharmacological and behavioural treatment of nicotine dependence.

8. The AMA will develop and support legislation or regulations that require tobacco companies to accurately label their products, indicating nicotine content in easily understandable and meaningful terms that have plausible, biological significance.

The authors gratefully acknowledge the editorial assistance of Marsha Meyer, American Medical Association.

1 Benowitz NL, Henningfield JE. Establishing a nicotine threshold for addiction. N Engl f Med 1994;331:123-5.

2 Benowitz NL, Henningfield JE. Regulation of the nicotine content of cigarettes (reply to letter). N Engl f Med 1994; 331:1531-2.

3 Peto R, Lopez AD, Boreham J, et al. Mortality from smoking in developed countries 1950-2000. New York: Oxford University Press, 1994.

4 Burns D. Estimation of risk reduction resulting from reduced number of cigarettes smoked per day. Paper presented at the annual meeting of the Society for Research on Nicotine and Tobacco, Nashville, Tennessee, 13-14 June 1997.

5 National Cancer Institute. Changes in cigarette-related disease risks and their implication for prevention and control. Bethesda, Maryland: National Institutes of Health, 1997. (NCI smoking and tobacco control monograph 8, NIH publication no 97-4213.)

6 Henningfield JE, Kozlowski LT, Benowitz NL. A proposal to develop a meaningful label for cigarettes. $\mathscr{f} A M A$ 1994; 272:312-14.

7 Hughes JR. Regulation of the nicotine content of cigarettes (letter). N Engl f Med 1994;331:1530-1.

8 US Centers for Disease Control and Prevention. Cigarette smoking among adults-United States, 1994. MMWR $1996 ; 45 \cdot 588-90$. 
9 US Centers for Disease Control and Prevention. Cigarette smoking among adults-United States, 1995. MMWR

10 US Centers for Disease Control and Prevention. Tobacco use and usual source of cigarettes among high school students-United States, 1995. MMWR 1996;45:413-18.

11 US Food and Drug Administration. Regulations restricting sale and distribution of cigarettes and smokeless tobacco products to protect children and adolescents; final rule.

12 US Food and Drug Administration. 21 CFR Part 801, et al. Regulations restricting sale and distribution of cigarettes and smokeless tobacco products to protect children and adolescents; final rule. Federal Register 1996;61(Aug 28):44395-618.

13 Burns D, Benowitz NL, Connolly G, et al. What should be the elements of any settlement with the tobacco industry? Tobacco Control 1997;6:1-4.

14 Henningfield JE. Postscript. Tobacco Control 1997;6(suppl 1):S98-9.

15 Koop CE, Kessler DA. Final report of the advisory committee on tobacco policy and public health. Tobacco Control 1997;6:254-61.

16 Humphrey HH III. Winning against big tobacco. Let's take the time to get it right. Public Health Rep 1997;112:378-85.

17 US Department of Health and Human Services. The health consequences of smoking: nicotine addiction. A report of the Surgeon General, 1988. Rockville, Maryland: Public Health Service, Centers for Disease Control, Office on Smoking
and Health, 1988. (DHHS Publication No (CDC) 88-8406.)

18 Perkins KA, Grobe JE, D'Amico D, et al. Low-dose nicotine nasal spray use and effects during initial smoking cessation. Exp Clin Psychopharmacol 1996;4:157-65.

19 Perkins KA, Grobe JE, Caggiula A. Acute reinforcing effects of low-dose nicotine nasal spray in humans. Pharmacol Biochem Behav 1997;56:235-41.

20 Bickel WK, Hughes JR, DeGrandpe RJ, et al. Behavioral economics of drug self-administration. IV. The effects of response requirement on the consumption of and the interaction between concurrently available coffee and cigarettes. Psychopharmacology 1992;107:211-16.

21 Henningfield JE, Schuh LM, Jarvik ME. Pathophysiology of tobacco dependence. In: Bloom FE, Kupfer DJ, eds. Psychopharmacology: the fourth generation of progress. New York: Raven Press, 1995:1715-29.

22 Henningfield JE, Keenan RM. Nicotine delivery kinetics and abuse liability. $\mathcal{F}$ Consult Clin Psychol 1993;61:743-50.

23 Benowitz NL. Pharmacology of nicotine: addiction and therapeutics. Annu Rev Pharmacol Toxicol 1996;36:597613.

24 American Psychiatric Association. Diagnostic and statistical manual of mental disorders, 4th ed. Washington, DC: American Psychiatric Association; 1994:242-7.

25 US Centers for Disease Control and Prevention. Reasons for tobacco use and symptoms of nicotine withdrawa among adolescent and young adult tobacco users-United States, 1993. MMWR 1994;43;745-50.

26 Shiffman S, Paty JA, Gnys M, et al. Nicotine withdrawal in chippers and regular smokers: subjective and cognitive effects. Health Psychol 1995;14:301-9.

27 American Society of Addiction Medicine. Principles of addiction medicine. Chevy Chase, Maryland: American Society tion medicine. Chevy Chase, Mar
of Addiction Medicine, 1994.

28 O'Brien CP. Drug addiction and drug abuse: In: Molinoff PB, Ruddon RW, eds. Goodman and Gilman's The pharmacological basis of therapeutics, 9th ed. New York: McGrawHill, 1996:557-75.

29 Hughes JR. Dependence potential and abuse liability of nicotine replacement therapies. Biomed Pharmacother 1989;43:11-17.

30 Hughes JR, Gust SW, Keenan R, et al. Long-term use of nicotine vs placebo gum. Arch Intern Med 1991;151:19938.

31 Henningfield JE. Nicotine medications for smoking cessation. N Engl F Med 1995;333:1196-1203.

32 Butschky MF, Bailey D, Henningfield JE, Pickworth WB. Smoking without nicotine delivery decreases withdrawal in 12-hour abstinent smokers. Pharmacol Biochem Behav 1995;50:91-6.

33 Rose JE, Levin ED. Inter-relationships between conditioned and primary reinforcement in the maintenance of cigarette smoking. Br $\mathcal{F}$ Addict 1991;86:605-9.

34 Institute of Medicine. Growing up tobacco free: Preventing nicotine addiction in children and youths. Lynch BS, Bonnie RJ, eds. Washington DC: National Academy Press, 1994

35 Pierce JP, Gilpin EA. How long will today's adolescent smoker be addicted to cigarettes? Am $\mathcal{f}$ Public Health 1996;b:253-6.

36 US Department of Health and Human Services. Preventing tobacco use among young people. A report of the Surgeon General. Atlanta, Georgia: Public Health Service, Centers for Disease Control and Prevention, Office on Smoking and Health, 1994. (US Government Printing Office document S/N 017-001-00491-0.)

37 Gilpin EA, Pierce JP. Trends in adolescent smoking initiation in the United States: is tobacco marketing an influence? Tobacco Control 1997;6:122-7.

38 Wahlgren DR, Hovell MF, Slymen DJ, Conway TL, Hofstetter CR, Jones JA. Predictors of tobacco use initiation in adolescents: a two-year prospective study and theoretical discussion. Tobacco Control 1997;6:95-103.
39 US Centers for Disease Control and Prevention. Changes in cigarette brand preferences of adolescent smokersUnited States, 1989-1993. MMWR 1994;43:577-81.

40 Slade J, Connolly GN, Davis RM, et al. Report of the tobacco policy research study group on tobacco products. Tobacco Control 1992;1(suppl):S4-9.

41 Chaloupka FJ, Wechsler H. Price, tobacco control policies and smoking among young adults. If Health Econ 1997;16:359-73.

42 Huber GL, Pandina RJ. The economics of tobacco use. In: Bolliger CT, Fagerström KO, eds. The tobacco epidemic. Progress in respiratory research. Basel: Karger, 1997:12-63.

43 Schwartz J. Tobacco pact's fine print limits action on nicotine: FDA authority threatened, opponents say. Washington Post 1997 Jul 8:A4.

44 Hwang SL, Freedman AM. B.A.T. considered patches but stuck to making cigarettes. Wall Street fournal 1995 Oct 9:B3.

45 Warner KE, Slade J, Sweanor DT. The emerging market for long-term nicotine maintenance. $\mathscr{f} A M A$ 1997;278:108792.

46 Warner KE, Peck CC, Woosely RL, et al. Treatment of tobacco dependence: innovative regulatory approaches to reduce death and disease: preface. Food Drug Law f 1998; 53(suppl): $1-9$.

47 Page JA. Federal regulation of tobacco products and products that treat tobacco dependence: are the playing fields level? Food Drug Law f 1998;53(suppl): 11-42.

48 Slade J, Henningfield JE. Tobacco product regulation: context and issues. Food Drug Law 7 1998;53(suppl):43-74.

49 Henningfield JE, Slade J. Tobacco-dependence medications: public health and regulatory issues. Food Drug Law $\mathcal{f}$ 1998;53(suppl):75-114

50 National Cancer Institute. The FTC cigarette test method for determining tar, nicotine, and carbon monoxide yields of US cigarettes. Report of the NCI Expert Committee. Bethesda, Maryland: National Cancer Institute, National Institutes of Health, 1996. (NCI Smoking and Tobacco Control Monograph 7, NIH Publication No. 96-4028.)

51 Regulation of Tobacco Products (Part I). Testimony of William I Campbell before the Subcommittee on Health and the Environment, Committee on Energy and Commerce, US House of Representatives, 25 March and 14 April 1994.

52 Kozlowski LT. Reduction of tobacco health hazards in continuing users: individual behavioral and public health approaches. I Substance Abuse 1989;1:345-57.

53 Rickert WS. Report of Canada's Expert Committee on Cigarette Modifications. Proceedings of conference held in Toronto, Ontario, Canada, 1-3 March 1996.

54 Hughes JR, Gulliver SB, Fenwick JW, et al. Smoking cessation among self-quitters. Health Psychol 1992;11:311-34.

55 Giovino GA, Henningfield JE, Tomar SL, et al. Epidemiology of tobacco

56 McLellan AT, Childress AR, Ehrman R, et al. Extinguishing conditioned responses during opiate dependence treatment. Turning laboratory findings into clinical procedures. F Substance Abuse Treat 1986;3:33-40.

57 West RJ, Russell MAH. Cardiovascular and subjective effects of smoking before and after $24 \mathrm{~h}$ of abstinence from cigarettes. Psychopharmacology 1987;92:118-21.

58 Henningfield JE, Jasinski DR. Pharmacological basis for nicotine replacement. In: Pomerleau OF, Pomerleau CS, Fagerström KO, et al. eds. Nicotine replacement: a critical evaluation. New York: Alan R Liss, 1988:35-61.

59 Jasinski DR, Henningfield JE. Conceptual basis of replacement therapies for chemical dependence. In: Pomerleau OF, Pomerleau CS, Fagerström KO, eds. Nicotine replacement: a critical evaluation. New York: Alan R Liss, 1988:13-34.

60 Perkins KA, Sanders M, D'Amico D, et al. Threshold dose for discrimination of nicotine in humans. Presented at the 3rd Annual Meeting of the Society for Research on Nicotine and Tobacco, Nashville, Tennessee, June 1997.

61 Perkins KA, DiMarco A, Grobe JE, et al. Nicotine discrimination in male and female smokers. Psychopharmacology 1994;116:407-13.

62 Goldberg SR, Henningfield JE. Reinforcing effects of nicotine in humans and experimental animals responding under intermittent schedules of IV drug injection. Pharmacol Biochem Behav 1988;30:227-34.

63 Meisch RA. Ethanol self-administration: infrahuman studies. In: Advances in Behavioral Pharmacology, Vol 1. New York: Academic Press, 1977:35-84.

64 Meisch RA, Thompson T. Ethanol as a reinforcer: effects of fixed ratio size and food deprivation. Psychopharmacologia 1973;28:171-83.

65 Valentine JD, Hokanson JS, Matta SG, et al. Selfadministration in rats allowed unlimited access to nicotine. Psychopharmacology 1997;133:300-4.

66 Slade J. Adolescent nicotine use and dependence. Adolescent Medicine State of the Art Reviews 1993;4:305-20.

67 Pritchard WS, Robinson JH, Guy TC, et al. Assessing the sensory role of nicotine and cigarette smoking. Psychopharmacology 1996;120:55-62.

68 Robinson JH, Pritchard WS, Davis RA. Psychopharmacological effects of smoking a cigarette with typical "tar" and carbon monoxide yields with minimal nicotine. Psychopharmacology 1992;108:466-72.

69 US Department of Health and Human Services. The health consequences of smoking: the changing cigarette. A report of the Surgeon General, 1981. Rockville, Maryland: Public Health 
Service, Office of the Assistant Secretary for Health, Office on Smoking and Health, 1981. (DHHS Publication No (PHS) 81-50156.)

70 Adams JM, Braunshteyn MS, Counts ME, et al. Cigarette and method of manufacturing cigarette for electrical smoking system. Assignee: Philip Morris Incorporated. US Patent 5,666,976, issued 16 September 1997.

71 Counts ME, Houck WG Jr, Houghton KS, et al. Electrical smoking article having continuous tobacco flavor web and flavor cassette therefore. Assignee: Philip Morris Incorporated. US Patent 5,479,948, issued 2 January 1996.

72 Counts ME, Deevi SC, Fleischhauer GS, et al. Electrical smoking system for delivering flavors and methods for making same. Assignee: Philip Morris Incorporated. US making same. Assignee: Philip Morris Incorpor

73 Freedman AM. 'Impact booster'. Tobacco firm shows how ammonia spurs delivery of nicotine. Wall Street fournal ammonia spurs

74 Hajaligol MR, Fleischhauer GS, Deevi SC, et al. Tubular heater for use in electrical smoking article. Assignee: Philip Morris Incorporated. US Patent 5,665,262, issued 9 September 1997.

75 Higgins CT, Raymond WR, Sprinkel FM. Electrical smoking article using liquid tobacco flavor medium delivery system. Assignee: Philip Morris Incorporated. US Patent $5,666,977$, issued 16 September 1997.

76 Slade J, Bero LA, Hanauer P, et al. Nicotine and addiction: the Brown \& Williamson documents. FAMA 1995; 274:225-33.

77 Djordjevic MV, Fan J, Ferguson S, et al. Self-regulation of smoking intensity. Smoke yields of the low-nicotine, low- 'tar' cigary. Carcinogenesis 1995;16:2015-21.

78 Djordjevic MV, Hoffmann D, Hoffmann I. Nicotine regulates smoking patterns. Prev Med 1997;26:435-40.

79 Hoffmann D, Hoffmann I. The changing cigarette, 19501995. F Toxicol Environ Health 1997;50:307-64.

80 Hoffmann D, Djordjevic MV, Hoffmann I. The changing cigarette. Prev Med 1997;26:427-34.

81 Thun MJ, Day-Lally CA, Calle EE, et al. Excess mortality among cigarette smokers: changes

82 Thun MJ, Lally CA, Flannery JT, et al. Cigarette smoking and changes in the histopathology of lung cancer. 7 Nat Cancer Inst 1997;89:1580-6.

83 Benowitz NL, Jacob P III, Yu L, Talcott R, et al. Reduced tar, nicotine and carbon monoxide exposure while smoking ultralow, but not low-yield cigarettes. $\mathcal{F} A M A$ 1986;256:241-6.

84 Kozlowski LT, Pillitteri JL. Compensation for nicotine by smokes of lower yield cigarettes. In: The FTC cigarette test method for determining tar, nicotine, and carbon monoxide yields of US cigarettes. Report of the NCI Expert Committee on Smoking and Tobacco Control. Bethesda, Maryland: National Cancer Institute, National Institutes of Health, 1996:161-172. (NCI Smoking and Tobacco Control Monograph 7, NIH Publication No. 96-4028.)

85 Massachusetts Department of Public Health 1997 cigarette nicotine disclosure report. Boston, Massachusetts: Massachusetts tine disclosure report. Boston, Massachusetts: Massachusetts Department of Public Health, 16 January 1998. <

86 Benowitz NL, Kuyt F, Jacob P III. Circadian blood nicotine concentrations during cigarette smoking. Clin Pharmaco Therapeut 1982;32:758-64.

87 Russell MAH, Sutton SR, Iyer R, et al. Long-term switching to low-tar low-nicotine cigarettes. $\mathrm{Br} \mathcal{F}$ Addict 1982; 77:145-58

$88 \mathrm{McGovern}$ PG, Lando HA. Reducing nicotine exposure and abstinence outcome in two nicotine fading methods. Addict Behav 1991;16:11-20.

89 Hughes JR, Hatsukami DK. Signs and symptoms of tobacco withdrawal. Arch Gen Psychiatr 1986;43:289-94

90 American Psychiatric Association. Practice guidelines for the treatment of patients with nicotine dependence. $A m \mathcal{F}$ Psychiatr 1996;153(suppl): 1-31.

91 Covey LS, Glassman AH, Stetner F. Major depression following smoking cessation. Am $f$ Psychiatr 1997; 154:263-5.

92 Glassman AH, Helzer JE, Covey LS, et al. Smoking, smoking cessation, and major depression. FAMA 1990; 264:1546-9

93 Henningfield JE. Pharmacologic basis and treatment of cigarette smoking. F Clin Psychiatr 1984;45:24-34.

94 Hughes JR. Treatment of smoking cessation in smokers with past alcohol/drug problems. F Substance Abuse Treatment 1993;10:181-7.

95 Hurt RD, Eberman KM, Slade J, et al. Treating nicotine addiction in patients with other addictive disorders. In: Orleans CT, Slade J, eds. Nicotine addiction: principles and management. New York: Oxford University Press, 1993:310-26

96 Double diagnosis: double dilemma (special issue). $\mathcal{f}$ Clin Psychiatr 1984;4-5:1-44.

97 US Department of Health and Human Services. Alcohol and tobacco: from basic science to clinical practice. Bethesda, Maryland: National Institutes of Health, National Institute on Alcohol Abuse and Alcoholism, 1995. (NIAAA Research Monograph No. 30, NIH Publication No. 95-3931.)

98 Fiore MC, Bailey WC, Cohen SJ, et al. Smoking cessation. Clinical Practice Guideline No 18. Rockville, Maryland:
US Department of Health and Human Services, Public Health Service, Agency for Health Care Policy and Health Service, Agency for Health Care Policy and
Research, April 1996. (AHCPR Publication No 96-0692.)
99 Benowitz N, Pinney J. Nicotine preparations in smoking. In Korting HC, Schafer-Korting M, eds. The benefit/risk ratio: a handbook for the rational use of potentially hazardous drugs. Boca Raton, Florida: CRC Press, $1998: 307$

100 Benowitz H, ed. Nicotine safety and toxicity. New York: Oxford University Press, 1998

101 Benowitz NL, Fitzgerald GA, Wilson M, et al. Nicotine effects on eicosanoid formation and hemostatic function: comparison of transdermal nicotine and cigarette smoking. F Am Acad Cardiol 1993;22:1159-67.

102 Oncken CA, Hatsukami DK, Lupo VR, et al. Effects of short-term use of nicotine gum in pregnant smokers. Clin Pharmacol Therapeutics 1996;59:654-61.

103 Oncken CA, Hardardottir H, Hatsukami DK, et al. Effects of transdermal nicotine or smoking on nicotine concentrations and maternal-fetal hemodynamics. Obstet Gynecol 1997;90:569-74.

104 Joossens L, Raw M. Smuggling and cross-border shopping in Europe. BMf 1995;310:1393-7.

105 Bonner R, Drew C. Cigarette makers are seen as aiding rise in smuggling. New York Times 1997 Aug 25:A1.

106 Joossens L, Raw M. Cigarette smuggling in Europe: who really benefits? Tobacco Control 1998;7:66-71.

107 Shepherd PL. Transnational corporations and the international cigarette industry. In: Newfarmer RS, ed. Profits, progress and poverty. South Bend, Indiana: University of Notre Dame, 1985.

108 Warner KE. Cigarette excise taxation and interstate smuggling: an assessment of recent activity. Natl Tax $\mathcal{F}$ 1982;35:483-90.

109 Lichtenstein E. Implications of the AHCPR guideline for psychological practice and research. Tobacco Control 1997; 6(suppl 1):S43-6.

110 Ockene JK, Zapka J. Changing provider behavior: provider education and training. Tobacco Control 1997;6(suppl 1):S63-S67.

111 Edmunds $M$. Clinical practice guidelines: opportunities and implications. Ann Behav Med 1996;18:126-32.

112 Abrams DB, Orleans CT, Niaura RS, et al. Integrating individual and public health perspectives for treatment of tobacco dependence under managed health care: a combined stepped-care and matching model. Ann Behav Med 1996;18:290-304.

113 Baron JA. Beneficial effects of nicotine and cigarette smoking: the real, the possible and the spurious. $B M F$ 1996;52:58-73.

114 Newhouse PA, Hughes JR. The role of nicotine and nicotine mechanisms in neuropsychiatric disease. $B r f$ Addict 1991;86:521-6.

115 Smoking cessation: alternative strategies. Proceedings of a national conference convened by the Behavioral Biology Research Center at the Johns Hopkins University School of Medicine and the Society for Research on Nicotine and Tobacco. Tobacco Control 1995;4(suppl 2):S1-90.

116 Chapman $S$. Industry down again down under. Tobacco Control 1995;4:17-18.

117 Mahood G. Canadian tobacco package warning system. Tobacco Control 1995;4:10-14.

118 Fiore MC, Novotny TE, Pierce JP, et al. Methods used to quit smoking in the United States: do cessation programs help? FAMA 1990;263:2760-5.

119 Cohen S, Lichtenstein E, Prochaska JO, et al. Debunking myths about self-quitting. Am Psychologist 1989;44:135565.

120 Davis RM. The delivery of smoking cessation services: current status and future needs. Tobacco Control 1993; 2(suppl):S63-9.

121 Orleans CT. Review of the current status of smoking cessation in the USA: progress and opportunities. Tobacco Control 1995; 4(suppl 2):S3-9.

122 Orleans CT. Welcome. Tobacco Control 1997;6(suppl 1):S2.

123 Pinney JM. Review of the current status of smoking cessation in the USA: assumptions and realities. Tobacco Control 1995;4(suppl 2):S10-14.

124 Pinney JM. Preface. Tobacco Control 1997;6(suppl 1):S1.

125 Abrams DB. Treatment issues: toward a stepped care model. Tobacco Control 1993;2(suppl):S17-29.

126 Ahluwalia JS. Reaching the medically underserved with the AHCPR guideline. Tobacco Control 1997;6(suppl 1):S2932

127 McClure JB, Skaar K, Tsoh JT, et al. Smoking cessation 3: needed healthcare policy changes. Behav Med 1997;23:2934.

128 US Centers for Disease Control and Prevention. Impact of promotion of the Great American Smokeout and availability of over-the-counter nicotine medications, 1996. $M M W R$. 1997;46:867-71.

129 Shiffman S, Gitchell J, Pinney JM, et al. Public health benefit of over-the-counter nicotine medications. Tobacco Control 1997;6:306-10

130 Lawrence WF, Smith SS, Baker TB, et al. Does over-the-counter nicotine replacement therapy improve smokers' life expectancy? Tobacco Control 1998. In press.

131 Slade J, Connolly GN, Davis RM, et al. Report of the tobacco policy research study group on adjunctive medications for managing nicotine dependence. Tobacco Control 1992;1(suppl):S10-13.

132 US Department of Health and Human Services. Cigars: health effects and trends. Bethesda, Maryland: National Institutes of Health, National Cancer Institute, 1998. (NCI Smoking and Tobacco Control Monograph 9, NIH Publication No. 98-4302.)

133 Gorodetsky CW. Product implications. Tobacco Control 1995;4(suppl 2):S57-9. 
134 Schuh LM, Henningfield JE. Nicotine replacement treatment and public health interventions: toward a marriage of two approaches. In: Slama K, ed. Tobacco and health. Proceedings of the ninth world conference on tobacco and health, 10-14 October 1994. New York: Plenum Press, 1995.

135 Selected excerpts from conference proceedings. Food Drug Law F 1998;53 (suppl): 115-37.

136 Robinson RG, Barry M, Bloch M, et al. Report of the tobacco policy research study group on marketing and promotions targeted at African Americans, Latinos, and women. Tobacco Control 1992;1(suppl):S24-30.

137 Sweanor D, Ballin S, Corcoran RD, et al. Report of the tobacco policy research study group on tobacco pricing and taxation in the United States. Tobacco Control 1992;1(suppl):S31-6.

138 Warner KE, Butler J, Cummings KM, et al. Report of the tobacco policy research study group on tobacco marketing tobacco policy research study group on tobacco marketing
and promotion. Tobacco Control 1992;1(suppl):S19-23.

139 RJR MacDonald, Inc. Memo dated 4 June 1997, from Rich Kauffeld to Lance Newman and Steve Wilson, regarding "Market incidence and usage".
140 Russell MAH. Low-tar medium-nicotine cigarettes: a new approach to safer smoking. BMF 1976;1:1430-3.

141 United Nations Conference on Trade and Development. Roundtable on social and economic aspects of reduction of tobacco smoking by use of alternative delivery systems. United Nations Conference on Trade and Development, Geneva, 22-24 September 1997.

142 Raw M. Regulating nicotine delivery systems: harm reduction and the prevention of smoking-related disease. Summary of a meeting held in November 1996, at the Health Education Authority in London. London: Hamilton House, 1997.

143 Ferrence R, Room R, Pope M, et al, eds. Nicotine and public health. Proceedings of a meeting held in Toronto. Sponsored by the Addiction Research Foundation (Toronto) and the American Society of Addiction Medicine (Chevy Chase, Maryland), March 1997.

144 Djordjevic MV, Brunnemann KD, Hoffman D. The need for regulation of carcinogenic N-nitrosamines in oral snuff. Food Chem Toxicol 1993;31:497-501.

Continued from page 280

\title{
Tobacco in history
}

\author{
“THE CIGARETTE HABIT”, BY JC MULHALL, 1895
}

Excerpt 3 (actions of nicotine, tolerance, effects on youth, peer pressure)

The only narcotic present (in cigarettes) is nicotine, and this is an evil or not according to a great many different circumstances. That chief circumstance when, without exception, it is always productive of great harm, is youth. Every medical man will admit, theoretically, that this should be a fact, and the few who, like myself, have made practical observations will tell you that they never saw a child (I mean by this term those who have not reached puberty) who used tobacco habitually whose health was not in some manner badly impaired. What else would one expect the tender, growing nervous organism to do but wilt under the steady daily influence of a drug like nicotine? In adolescence-and practically this may be said to be from puberty until eighteen in females and twenty-one in males - the evil is not so great, but is still a great one; for, though the nervous crisis of puberty has been passed, the nervous system is still rapidly developing. The nerves are more resistant than in childhood, but, on the other hand, greater demands are correspondingly made upon them, either by the higher phases of education in one class or by the actual daily struggle for existence in the other. That the use of tobacco is a serious handicap in adolescence is proved by the investigations of others than myself. At several of our great universities it has been found by exact and scientific investigation that the percentage of winners in intellectual and athletic contests is considerably higher in the total abstainers from tobacco. Sammy, the best known newsboy of St. Louis, who by his wit and energy at the age of fourteen has accumulated quite a bank account, at my instigation made a series of unbiased observations concerning the newsboys of St. Louis. He found, among things being equal, that the selling capacity of the boy who used no tobacco was much greater than that of the boy who used tobacco either by chewing or by smoking. ...

The boy at first uses only the mouth as a smoke chamber, and as a cigarette is so mild he absorbs but a minute quantity of nicotine, insufficient for nausea. $\mathrm{He}$ gradually becomes able to consume more cigarettes, and quickly acquires nicotine tolerance. He is not allowed to pursue this method long. Invariably some other boy teaches him to inhale. At first it causes violent cough and many would never repeat the attempt, but the taunts of the other boy are heard, and with the bravado of boyhood he perseveres. The larynx and windpipe soon tolerate the smoke, then demand it, and the boy is a full-fledged cigarette fiend. 